6 th Conference on the Intersections of Particle \& Nuclear Physics

Big Sky, Montana May 27-June 2, 1997

$$
\text { CONF-970564 - }
$$

\title{
The BNL AGS Accelerator Complex Status And Future Plans
}

\author{
Mitsuyoshi Tanaka \\ AGS Department, Brookhaven National Laboratory* \\ Upton NY 11973, USA
}

\begin{abstract}
This paper describes the present performance and capability of the BNL AGS accelerator complex and possible future intensity upgrade plans. In 1995, the AGS reached its design upgrade goal of $6.0 \cdot 10^{13} \mathrm{ppp}$ with the Booster. The AGS with a new fast extracted beam (FEB) system is able to perform single bunch multiple extraction at $30 \mathrm{~Hz}$ per AGS cycle for the g-2 experiment and for RHIC injection.
\end{abstract}

\section{INTRODUCTION}

In July 1960, the BNL Alternating Gradient Synchrotron (AGS) accelerated protons to $30 \mathrm{GeV}$ at an intensity of $\sim 10^{10} \mathrm{ppp}$--becoming the world's most powerful atom smasher. Since then, the AGS has been periodically upgraded, improved, and has evolved to satisfy its continuously changing user's wishes; e.g. the $50 \mathrm{MeV}$ Linac was replaced with the $200 \mathrm{MeV}$ Linac in 1970, the AGS was connected to the existing Tandem Van de Graaff Accelerator in 1983, the 1.5 GeV Booster was added in 1991, and the associated AGS subsystem upgrades were completed.

\section{RECENT PERFORMANCE AND ACHIEVEMENTS}

The AGS now accelerates heavy ions up to gold $\left(\mathrm{Au}^{77+}\right)$ at various energies for the heavy ion physics program and has recently increased the slow-extracted proton beam (SEB) intensity above $6.0 \cdot 10^{13} \mathrm{ppp}$ at $25 \mathrm{GeV} / \mathrm{c}$ with a $1.6 \mathrm{sec}$ uniform spill for various intensity hungry particle physics experiments such as rare K-decay experiments.

The accelerator also recently became equipped with a new FEB extraction system that allows the AGS to perform single bunch multiple extraction of a heavy ion or a (polarized) proton beam at a time interval of $33 \mathrm{~ms}$ up to 12 times

*Work performed under the auspices of the US Department of Energy. 
per AGS cycle for filling of the RHIC collider or for $3.0 \mathrm{GeV} / \mathrm{c} \pi / \mu$ production for the $14 \mathrm{~m}$ diameter $\mathrm{g}-2$ muon storage ring. In the fall of 1995, a single bunch of $0.25 \cdot 10^{9}$ gold ions was successfully extracted at $11.2 \mathrm{GeV} / \mathrm{c} / \mathrm{N}$ from the AGS and transported through the $600 \mathrm{~m}$ long AGS-to-RHIC (AtR) transfer line to an internal beam dump. The RHIC injection test, which includes the full AtR line and $1 / 6$ of the superconducting ring, was successfully completed in January 1997. The commissioning of V/V1 lines with protons was also completed for the g-2 ring, which is now storing muons for the muon anomalous magnetic moment $(\mathrm{g}-2)$ experiment (E821).

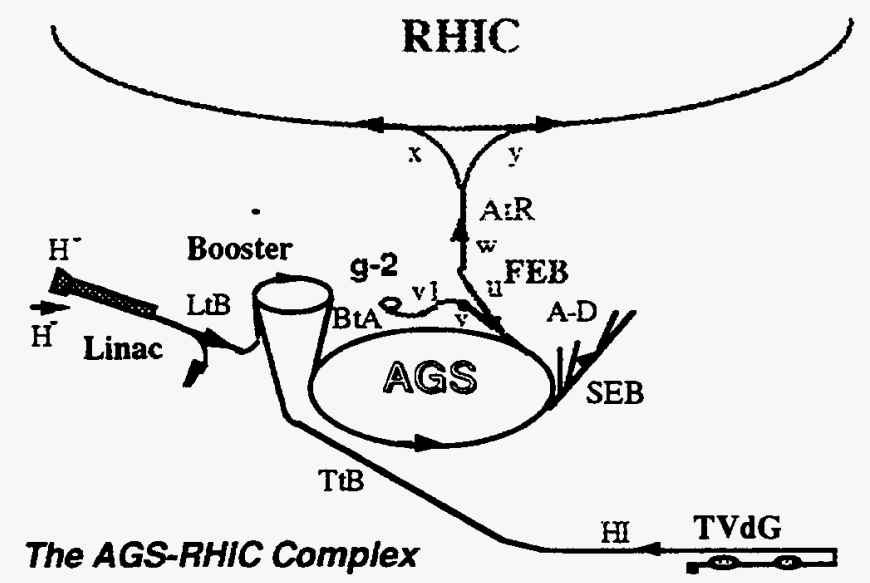

Figure 1. Schematic of the BNL AGS Accelerator Complex.

\section{POSSIBLE FUTURE UPGRADE PLANS}

So far we have focused mainly on increasing extracted beam intensity without much attention to the emittance blowup or beam loss. A better understanding of the critical high intensity effects can lead to better machine tuning, hence it could increase the intensity further. However, beyond $10^{14} \mathrm{ppp}$, various upgrades of the AGS are needed: 1) the AGS proton beam intensity could be further increased to $1.5 \times 10^{14} \mathrm{ppp}$ with the implementation of a barrier cavity if system by avoiding bunched beam stacking during injection [1], 2) by adding a 1.5 $\mathrm{GeV}$ accumulator ring in the AGS tunnel to accept beam continuously from the Booster during $1.2-2.5 \mathrm{sec}$ of the AGS cycle time, two to four times more beam pulses can be accumulated and be transferred into the AGS ring; 3) by increasing the AGS repetition rate to $2.5 \mathrm{~Hz}$, the average beam current could be pushed to $40 \mu \mathrm{A}[2]$

\section{SUMMARY}

There were/are several proposals (LAMPF II, KAON, JHP etc.) for a high intensity hadron facility around the world, but only one that is already in 


\section{DISCLAIMER}

This report was prepared as an account of work sponsored by an agency of the United States Government. Neither the United States Government nor any agency thereof, nor any of their employees, make any warranty, express or implied, or assumes any legal liability or responsibility for the accuracy, completeness, or usefulness of any information, apparatus, product, or process disclosed, or represents that its use would not infringe privately owned rights. Reference herein to any specific commercial product, process, or service by trade name, trademark, manufacturer, or otherwise does not necessarily constitute or imply its endorsement, recommendation, or favoring by the United States Government or any agency thereof. The views and opinions of authors expressed herein do not necessarily state or reflect those of the United States Government or any agency thereof. 
operation and under construction. It is the BNL AGS complex. It is being done by a step-wise, physics driven approach in the most cost-effective way to minimize the downtime to the ongoing physics program and the cost without a major up front commitment in funding. The AGS average beam current was 1 $\mu \mathrm{A}$ just a few years ago, it is now $3 \mu \mathrm{A}$, and will become 5-7 $\mu \mathrm{A}$ with a barrier bucket rf system and tuning. With an accumulator, which is under design, it will reach $12 \mu \mathrm{A}$.

After 1999, the AGS becomes an injector for RHIC to fill its two rings with gold or polarized proton beams in a few minutes every 8-10 hours, the AGS could be available between fillings for forefront particle and nuclear physics program at an incremental cost.

\section{ACKNOWLEDGMENTS}

The work described in this paper has been performed collectively by the accelerator staff in the AGS Department and the RHIC Project.

\section{REFERENCES}

1. M. Blaskiewicz and J.M. Brennan, A Barrier Bucket Experiment for Accumulating Debunched Beam in the AGS, Proc. of the Fifth European Particle Accelerator Conf., Sitges, Spain, 1996, p. 2373.

2. J.M. Brennan and T. Roser, High Intensity Performance of the Brookhaven AGS, Proc. of the Fifth European Particle Accelerator Conf., Sitges, Spain, 1996, p. 530. 
Report Number (14) BNL-64042 CONF-970564

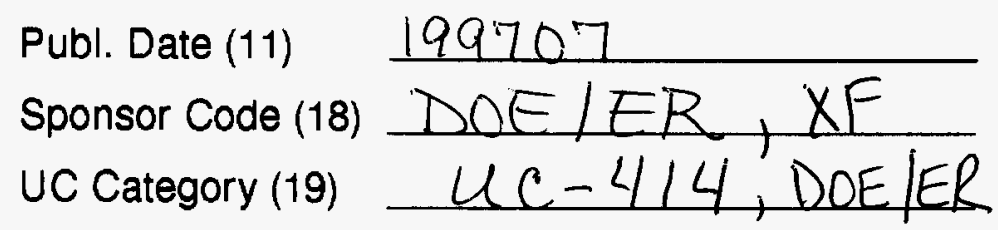

